\title{
Distribution of water in synthetic calcium silicate
}

\section{hydrates}

Roosz, C. ${ }^{1,2,3}$ Gaboreau, $S .{ }^{2}$, Grangeon, $S .{ }^{2}$, Prêt, $D .{ }^{1}$, Montouillout, $V .{ }^{4}$, Maubec, $N .{ }^{2}$,

Ory, S. $^{4}$, Blanc, $P .^{2}$, Vieillard, $P .{ }^{1}$, Henocq, $P .{ }^{3}$

\section{Helium pycnometry}

Grain or real density $\left(\rho_{\mathrm{gr}}\right)$ was determined in a micrometrics Accupix 1330 helium pycnometer. A ground sample was dehydrated by heating at $40^{\circ} \mathrm{C}$ under vacuum. The measurement was repeated five times for each sample to estimate a mean value and a precision based on the standard deviation. All the results are presented in Error! Reference source not found..

\section{Nuclear magnetic resonance}

The ${ }^{29} \mathrm{Si}$ MAS NMR spectra were acquired on a Bruker Advance $400 \mathrm{MHz}(\mathrm{B} 0=9.4 \mathrm{~T})$ operating at a Larmor frequency of $79.4 \mathrm{MHz}$ and with a spinning rate of $12 \mathrm{kHz}$. Each spectrum necessitated the sum of 30,000 to 40,000 transients accumulated with a recycling delay of $10 \mathrm{~s}$ ensuring complete magnetization relaxation. ${ }^{29} \mathrm{Si}$ chemical shifts are given relative to tetramethylsilane (TMS) at $0 \mathrm{ppm}$. 


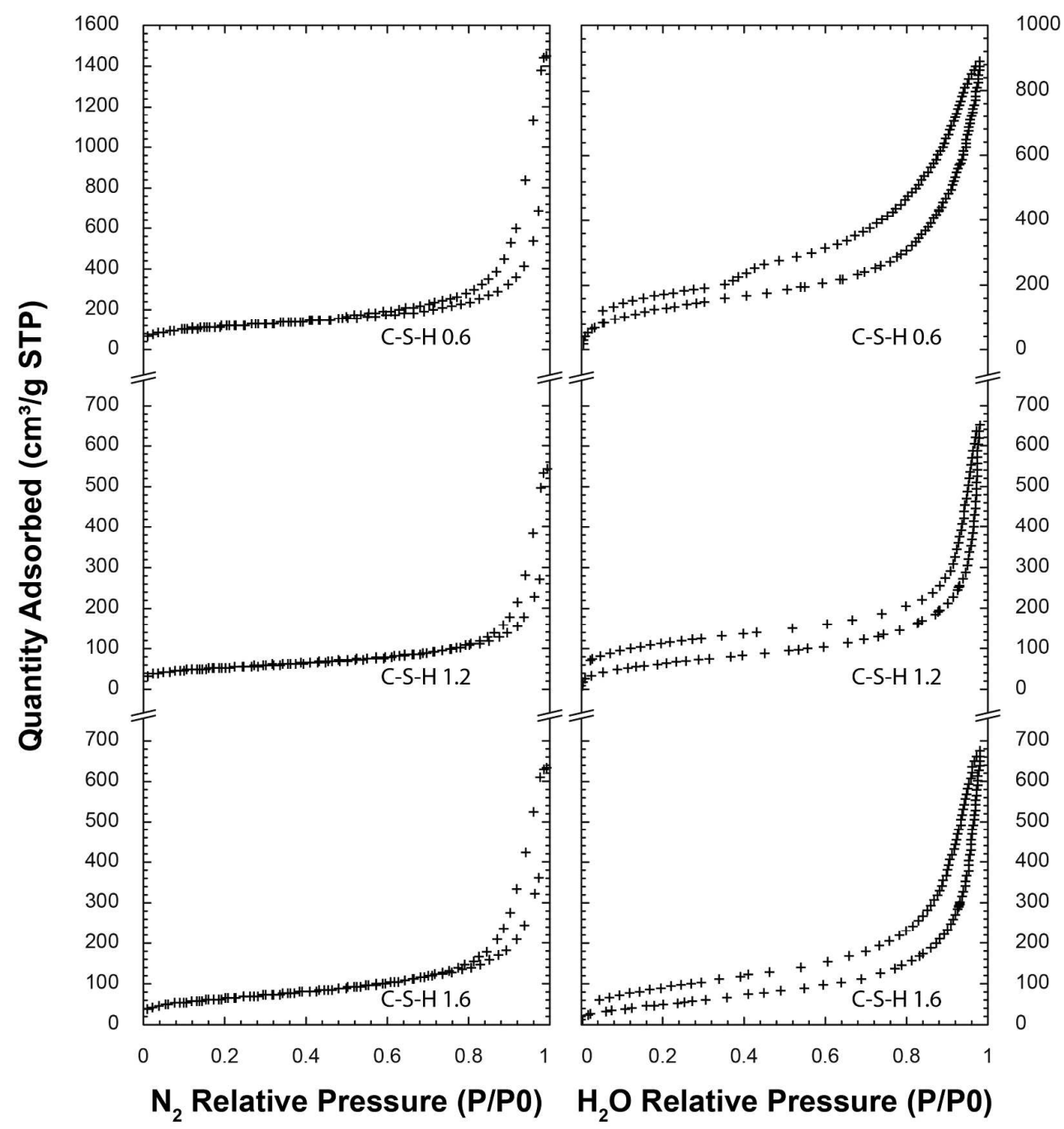

Figure SD1. Nitrogen and water vapor adsorption/desorption isotherms of C-S-H 0.6, 1.2 and 1.6 samples. 

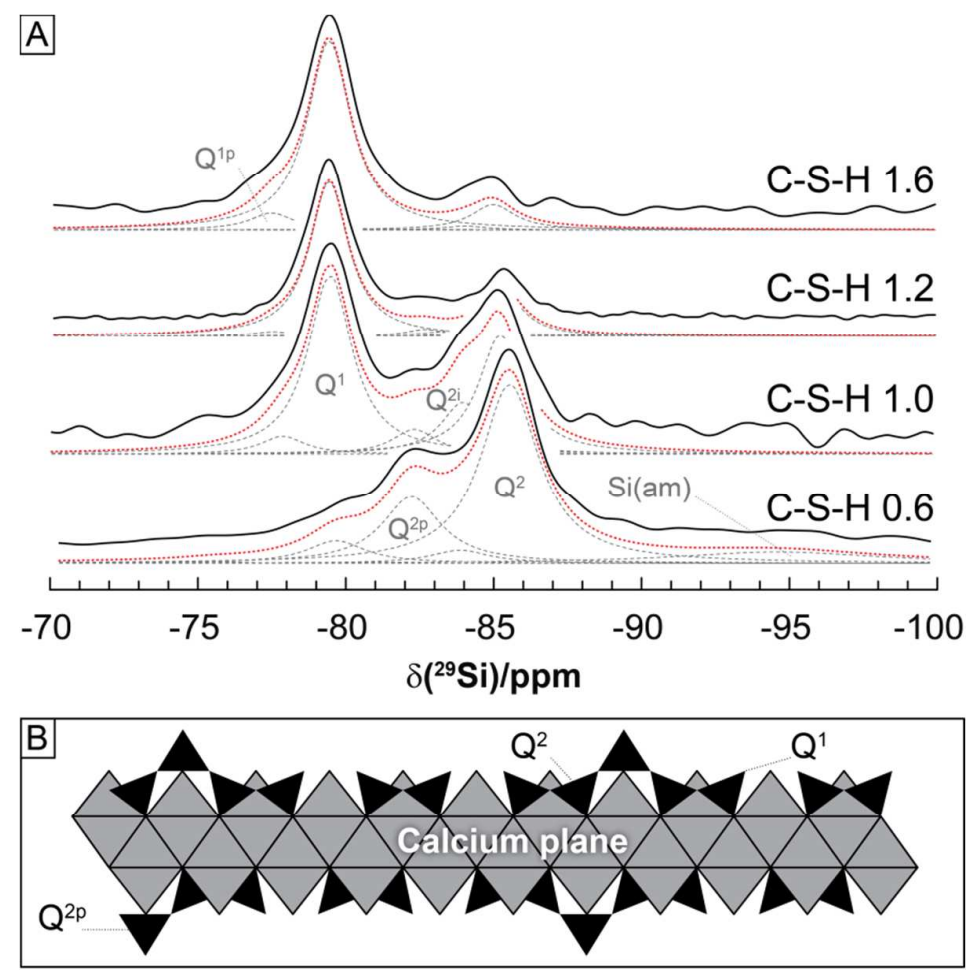

Figure SD2. A-Solid-state ${ }^{29} \mathrm{Si}$ MAS-NMR spectrum recorded on synthetic C-S-H samples. Dotted and red lines represent the deconvolution and the fitting results with a vertical offset. B-C-S-H schematic layer structure with the different silicon environments

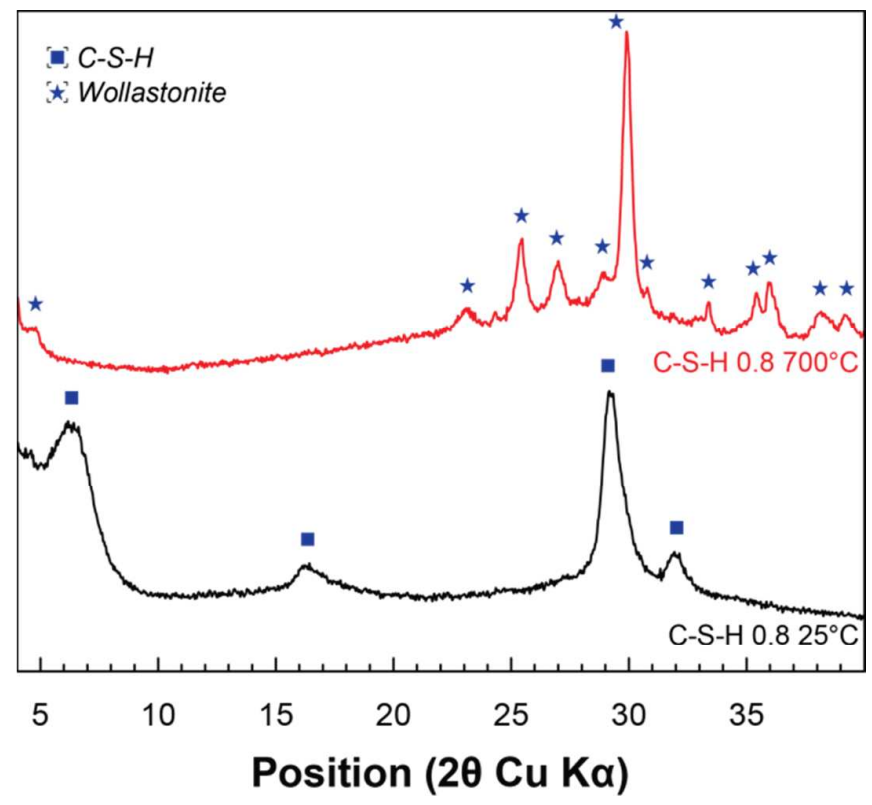

Figure SD3. XRD patterns of C-S-H 0.8 in fully hydrated state and after heating at $700^{\circ} \mathrm{C}$. 
Table SD1. Quantitative electron probe microanalyses of the synthesized C-S-H samples. The $\mathrm{Ca} / \mathrm{Si}$ ratios are calculated from the $\left(\mathrm{At}_{\mathrm{i}}\right) \mathrm{mol} \%$.

\begin{tabular}{|c|c|c|c|c|c|c|c|c|c|}
\hline Samples & $\begin{array}{c}\text { Target } \\
\mathrm{Ca} / \mathrm{Si}\end{array}$ & $\mathrm{Ca}$ & $\mathrm{Si}$ & $0^{*}$ & $\mathrm{Ca}$ & Si & 0 & $\begin{array}{l}\mathrm{Ca} / \mathrm{Si} \\
\text { ratio }\end{array}$ & $\begin{array}{c}\text { Number of } \\
\text { analyses }\end{array}$ \\
\hline & & \multicolumn{3}{|c|}{$\left(A t_{i}\right) w t \%$} & \multicolumn{3}{|c|}{$\left(A t_{i}\right) \mathrm{mol} \%$} & & \\
\hline C-S-H 0.6 & 0.6 & $21 \pm 0.1$ & $23 \pm 0.3$ & $35 \pm 0.4$ & $16 \pm 0.1$ & $23 \pm 0.3$ & $61 \pm 0.4$ & 0.69 & 100 \\
\hline C-S-H 0.8 & 0.8 & $25 \pm 0.2$ & $21 \pm 0.3$ & $34 \pm 0.5$ & $17 \pm 0.2$ & $21 \pm 0.3$ & $62 \pm 0.5$ & 0.82 & 100 \\
\hline C-S-H 1.0 & 1.0 & $27 \pm 0.2$ & $18 \pm 0.7$ & $32 \pm 0.9$ & $20 \pm 0.2$ & $20 \pm 0.7$ & $60 \pm 0.9$ & 1.06 & 100 \\
\hline C-S-H 1.2 & 1.2 & $31 \pm 0.3$ & $18 \pm 0.5$ & $32 \pm 0.8$ & $22 \pm 0.3$ & $18 \pm 0.5$ & $60 \pm 0.8$ & 1.23 & 100 \\
\hline C-S-H 1.6 & 1.6 & $31 \pm 0.4$ & $15 \pm 0.4$ & $29 \pm 0.4$ & $24 \pm 0.4$ & $17 \pm 0.4$ & $59 \pm 0.4$ & 1.42 & 100 \\
\hline
\end{tabular}

*Total stoichiometric oxygen calculated 